\title{
Increased intake of fruits and vegetables in overweight subjects: effects on body weight, body composition, metabolic risk factors and dietary intake
}

\author{
A. Järvi ${ }^{1}$, B. Karlström ${ }^{1}$, B. Vessby ${ }^{1}$ and W. Becker ${ }^{1,2 *}$ \\ ${ }^{1}$ Department of Public Health and Caring Sciences, Clinical Nutrition and Metabolism, Uppsala University, PO Box 564, \\ 75122 Uppsala, Sweden \\ ${ }^{2}$ Risk Benefit Assessment Department, National Food Agency, PO Box 622, Uppsala, Sweden
}

(Submitted 15 October 2015 - Final revision received 12 February 2016 - Accepted 16 February 2016 - First published online 21 March 2016)

\section{Abstract}

A diet rich in fruits and vegetables has been associated with several health benefits. However, the effects on body weight (BW) and metabolic markers are not fully known. The present study investigated the effects of increased intake of fruits and vegetables in overweight and obese men and women on dietary habits, anthropometry and metabolic control. In a 16-week controlled intervention, thirty-four men and thirty-four women aged 35-65 years $\left(\mathrm{BMI}>27 \mathrm{~kg} / \mathrm{m}^{2}\right.$ ) were randomised to an intervention (IN) or a reference (RG) group. All participants received general dietary advice, and subjects in the IN group received fruits and vegetables for free, of which $\geq 500 \mathrm{~g}$ had to be eaten daily. BW, waist circumference (WC), sagittal abdominal diameter (SAD), plasma insulin, blood glucose, glycated $\mathrm{Hb}$ (HbA1c), serum lipids, blood pressure, plasminogen activator inhibitor-1 activity, urinary isoprostane (iso-8-PGF $2 \alpha$ ) and serum carotenoids were measured. Diet was assessed using 3-d weighed food records. In all, thirty subjects in the IN group and thirty-two in the RG group completed the intervention. Intake of fruits and vegetables doubled in the IN group, whereas intake of fruits increased in the RG group. Serum $\alpha$ - and $\beta$-carotene concentrations and intakes of folate and vitamin $\mathrm{C}$ increased significantly in the IN group. Energy intake, BW, WC and SAD decreased significantly in both groups. Supine systolic blood pressure decreased significantly in the IN group, with no between-group differences. No significant changes were observed for other metabolic markers. Provision of fruits and vegetables led to substantially increased intakes, with subsequent favourable changes in anthropometry and insulin levels, which tended to be more pronounced in the IN group. The observed improvements may, in combination with improved nutritional markers, have health benefits in the long term.

\section{Key words: Fruits: Vegetables: Body weight: Food intakes: Metabolic markers}

During the past few decades, there has been an increased prevalence of overweight and obesity and type 2 diabetes $^{(1)}$ in most parts of the world. Overweight and obesity increase the risk for type 2 diabetes, CHD and some cancers ${ }^{(2-4)}$. Efforts made to decrease the prevalence of dietary-related diseases include nutrition- and food-based recommendations issued by organisations and authorities in different countries. These include the Nordic Nutrition Recommendations ${ }^{(4,5)}$ and recommendations on fat and fatty acids and carbohydrates issued by the Food and Agriculture Organization/ $/ \mathrm{WHO}^{(6,7)}$.

Fruits and vegetables are good sources of dietary fibre, vitamins and minerals and have a low energy density. A diet rich in fruits and vegetables has in some intervention studies been associated with favourable effects on metabolic risk factors including serum lipids, blood pressure $(\mathrm{BP})^{(8-12)}$ and body weight $(\mathrm{BW})^{(13-15)}$, although a lack of impact has also been reported ${ }^{(16,17)}$. Results from prospective cohort studies show inverse associations between fruit and vegetable intakes and stroke ${ }^{(18)}, \mathrm{CVD}^{(19)}$, total mortality $^{(19,20)}$ and some cancers ${ }^{(21-24)}$. Possible mechanisms/ mediators for the favourable effect of fruits and vegetables include reduced dietary energy density, modulation of blood lipid and glucose response and BW by dietary fibre, as well as replacement of less-favourable foods ${ }^{(4,25)}$. Evidence for mechanisms involving antioxidants is, however, limited ${ }^{(4)}$.

The impact of including an ample amount of fruits and vegetables to the diet on the overall food intake and subsequent effects on BW and metabolic risk factors is, however, not yet fully known. The Swedish food-based guidelines include advice to eat at least $500 \mathrm{~g}$ of fruits and vegetables per day, corresponding to about five portions a day ${ }^{(26)}$. Results from Swedish dietary surveys in adults show that mean intakes are well below the target of $500 \mathrm{~g} / \mathrm{d}^{(27,28)}$.

The overall objective of the present study was to investigate the effects of an increased intake of fruits and vegetables on BW, body composition and metabolic markers among overweight and obese men and women. The secondary aim was to study any influence on overall dietary habits.

All study subjects gave their informed consent for participation, and the study was approved by the Ethics Committee of Uppsala University (Dnr 00-035).

Abbreviations: BP, blood pressure; BW, body weight; E\%, percentage of energy; HbA1c, glycated Hb; IN, intervention; RG, reference; SAD, sagittal abdominal diameter.

* Corresponding author: W. Becker, email wulf.Becker@slv.se 


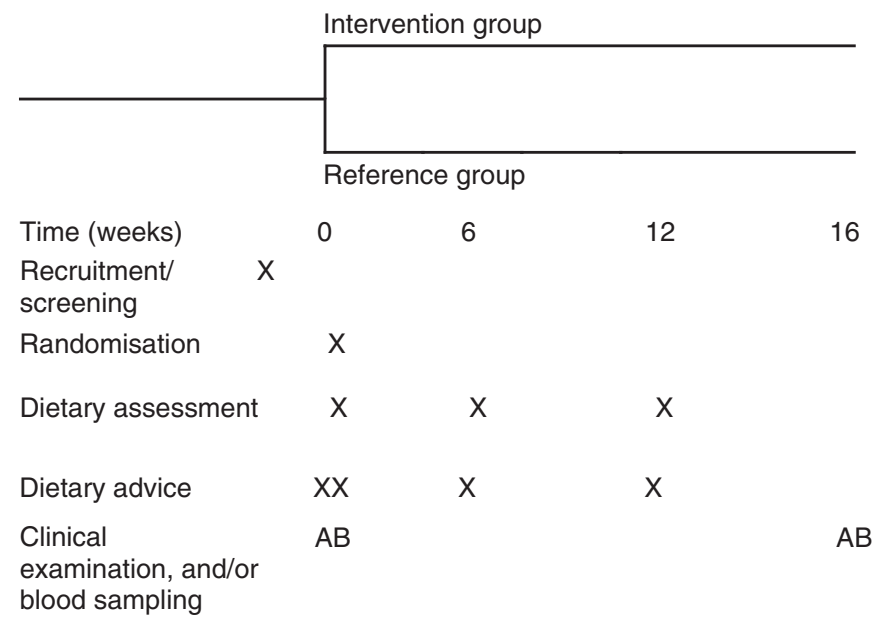

Fig. 1. Study design. Overview of timing of anthropometrical and clinical measurements and dietary assessment. X, indicates instances; A, blood pressure, body weight, waist circumference, sagittal abdominal diameter, fasting blood samples for the analysis of plasma insulin, blood glucose, glycated $\mathrm{Hb}$ (HbA1c), serum lipids (lipoproteins and apo), fatty acid composition of the serum phospholipids, fibrinolytic capacity (plasminogen activator inhibitor-1 activity), levels of antioxidative vitamins in plasma, lipid peroxidation (malondialdehyde) and 24-h collection of urine for the analysis of isoprostanes; B, body weight and blood samples for the analysis of TAG and cholesterol in serum, blood glucose and $\mathrm{HbA1c}$.

\section{Methods \\ Subjects}

Subjects were recruited via advertising in the local Uppsala newspaper. Subjects aged 35-65 years who were overweight $\left(\mathrm{BMI}>27 \mathrm{~kg} / \mathrm{m}^{2}\right)$ were invited to participate. In total, 375 women and seventy-seven men responded, and 320 women and seventy-three men fulfilled the requirements for age, weight and height. All men and 100 women, selected at random, were asked to respond to an initial questionnaire regarding state of health, use of drugs and health foods, food allergies and intolerances. In all, ninety-five women and fifty-five men met the inclusion criteria for age and BMI and were apparently healthy. All men and sixty-five randomly selected women were invited to a health and laboratory screening in order to exclude subjects with thyroid disease, kidney or liver damage, undiagnosed diabetes or high blood lipid levels. Of the screened subjects, thirty-four women and thirty-four men were included in the study.

\section{Dietary intervention}

Subjects were randomised into either an intervention (IN) or a reference (RG) group. Before randomisation, all participants received dietary advice from an experienced dietitian in line with the nutrition recommendations ${ }^{(5)}$. Dietary advice was given twice in groups of ten persons. The dietary advice given aimed at reducing total fat intake, decreasing the proportion of SFA, increasing the proportion of unsaturated fats, especially MUFA, increasing the intake of fish, increasing the intake of dietary fibre and increasing the intake of vegetables, roots, fruits and berries. The dietary advice given was food based, and participants were recommended to choose products labelled with the keyhole symbol ${ }^{(29)}$ and to use the plate model for meal planning ${ }^{(30)}$. Dietary advice was also given to both groups in connection with the dietary assessment during weeks
6 and 12. The participants were instructed not to change their physical activity during the study period.

Participants in the IN group received fruits and vegetables for free throughout the entire study period, and at least $500 \mathrm{~g}$ had to be eaten daily. All products were collected once a week at the outpatient clinic. Participants in the IN group were offered to receive the same amount of vegetables and fruits for one additional family member. All fruits and vegetables were given in portion sizes of approximately $100 \mathrm{~g}$. Recipes and instructions on how to prepare frozen vegetables for consumption were given to the participants as well as recipe folders. If the intake was $<500 \mathrm{~g} / \mathrm{d}$, the subjects were encouraged to increase their intake. The different fruits given to the IN group were apples, pears, kiwi fruit, bananas and oranges/clementines. The fresh vegetables provided were white cabbage, carrots, tomatoes, pepper, onions, leek and Chinese cabbage. The deep-frozen varieties were string beans (haricots verts), broccoli, green peas, sweet maize and three different varieties of mixed roots and vegetables. Fig. 1 shows the study design.

\section{Anthropometric and clinical measurements}

At baseline and at the end of the study, the subjects went through a clinical examination with measurements of BP, BW, waist circumference (WC) and sagittal abdominal diameter (SAD). Fasting blood samples were collected for the analysis of plasma insulin, blood glucose, glycated $\mathrm{Hb}$ (HbA1c), serum lipids, lipoproteins and apo, fatty acid composition of serum phospholipids, fibrinolytic capacity, levels of antioxidative vitamins in plasma and lipid peroxidation; 24-h urine samples were collected for the analysis of isoprostanes. In connection with the dietary assessments at 6 and 12 weeks, BW was measured and blood samples were collected for the analyses of TAG and cholesterol in serum as well as blood glucose and HbA1c.

Height was measured without shoes to the nearest $0.5 \mathrm{~cm}$ and BW was measured to the nearest $0 \cdot 1 \mathrm{~kg}$ without shoes in light 
indoor clothing. BMI was calculated as the BW $(\mathrm{kg})$ divided by the height squared $\left(\mathrm{m}^{2}\right)$. WC was measured midway between the lowest rib and the iliac crest. SAD (antero-posterior) was measured $^{(31)}$ in a recumbent position with the hips flexed.

$\mathrm{BP}$ was measured in the right arm with the subjects in the supine position after a 5-min rest period. Systolic BP (SBP) and diastolic BP (DBP) were defined as Korotkoff phases 1 and 5, respectively.

Blood samples were drawn from an antecubital vein, and all serum and plasma samples were stored at $-70^{\circ} \mathrm{C}$ until analysed, if not analysed directly. All fasting blood samples were collected after a 12-h overnight fast.

Blood glucose concentrations were determined by the glucose oxidase method. HbA1c was measured by fast-performance liquid chromatography assay. Plasma insulin was measured by enzyme immunoassay using an ELISA-kit (Mercodia AB).

TAG and cholesterol concentrations were measured enzymatically in serum and in the isolated lipoprotein fractions using a Monarch apparatus (Instrumentation Laboratories). The concentrations of serum apo A-1 and B were determined by an immunochemical assay (Orion Diagnostica). HDL-cholesterol was separated by precipitation with magnesium chloride/ phosphotungstate ${ }^{(32)}$. LDL-cholesterol was calculated using Friedewald's formula: LDL-cholesterol $=$ serum cholesterol HDL-cholesterol-( $0.45 \times$ serum TAG $)$.

Plasminogen activator inhibitor-1 activity (PAI-1 activity) in plasma was measured using Spectrolyse/pL kits from Biopool AB.

Serum $\alpha$ - and $\gamma$-tocopherol concentrations were determined using HPLC with fluorescence detection ${ }^{(33)}$ and were adjusted relative to serum lipid concentrations as suggested by Thurnham et al. ${ }^{(34)}$.

Serum carotenoids $(\alpha-, \beta$-), lutein and lycopene were determined by HPLC as described by Rytter et $a l{ }^{(35)}$, and were used mainly as biomarkers of fruit and vegetable intake.

Plasma malondialdehyde (MDA) concentration was measured by HPLC ${ }^{(36)}$, and urine 8 -iso-PGF $2 \alpha$ was analysed by a specific and validated RIA developed by Basu ${ }^{(37)}$. The levels of 8 -iso-PGF $2 \alpha$ in urine were adjusted for creatinine concentrations.

\section{Dietary assessments}

At baseline, participants completed a 3-d weighed dietary record before receiving dietary advice, which included 2 consecutive weekdays and $1 \mathrm{~d}$ during the weekend. The food intake was also recorded after 6 weeks and after 12 weeks, respectively. The food record was completed during the same weekdays and weekend days on all three occasions. Subjects received oral and written instructions from a dietitian, including details on food description. The food items were weighed to the nearest gram on an electronic kitchen scale (Soehnle) with a precision of $0 \cdot 1 \mathrm{~g}$.

\section{Follow-up}

After 1 year of completion of the study, participants in both groups were invited for a follow-up, which included the same measurements and blood sampling as at baseline and study completion. In addition, another 3-d weighed food record was obtained.

\section{Dietary analysis}

Energy and nutrient intakes were calculated using commercial dietary analysis software (MAT, version 4.03; Rudans lättdata), which includes the Swedish National Food Agency's food composition database (version 04.1.1). The nutrient composition of dishes was calculated using subject-specific recipes according to the food records or standard recipes. For a few food products, values were obtained from the manufacturer or calculated based on similar foods in the food composition database.

\section{Statistical analyses}

The statistical analysis was performed using SAS for Windows, version 8.0 (SAS Institute), and Minitab for Windows, version 15 (Minitab Inc.), using the general linear model (GLM) for differences between groups and pair-wise $t$ tests for changes within groups. $P$ values $<0.05$ were considered significant. Data on significances are presented for between-group differences at baseline as well for within-group and between-group changes during the intervention. Power calculations were performed for BMI. In all, thirty participants in each group were estimated to allow detection of a difference in BMI of 2 units with $80 \%$ power at $P<0.05$.

\section{Results}

In total, sixty-two of the sixty-eight subjects (thirty in the IN and thirty-two in the RG group) completed the 16-week intervention, corresponding to $91 \%$ participation. Baseline data for these are given in Table 1 . There were no differences between dropouts and study participants. In total, forty-nine subjects (twenty-four in the IN and twenty-five in the RG group) participated in the follow-up 1 year after the intervention period was completed.

\section{Anthropometry}

BW, BMI, WC and SAD did not differ significantly between the two groups at baseline (Table 1). At the end of the study period, BW, WC and SAD had decreased significantly in both groups, but without any significant between-group differences in change during the intervention. BMI decreased significantly from baseline in both groups.

\section{Metabolic and clinical variables}

No significant changes were seen for major serum lipids or apo in either group during the intervention period (Table 1).

At baseline, insulin levels were $70 \%$ higher (NS) in the RG than in the IN group (Table 1). At the end of the intervention period, levels had decreased in both groups, being statistically significant in the IN group $(P<0.05)$, without significant between-group differences. No significant changes were seen for plasma glucose. Minor, but significant $(P<0.05)$, increases in HbA1c concentrations were seen in both groups. 
Table 1. Anthropometric, clinical variables, serum carotenoids and tocopherols at baseline and at end of the study period for subjects who participated at baseline and at the end of the intervention (IN) period

(Mean values and standard deviations)

\begin{tabular}{|c|c|c|c|c|c|c|c|c|c|}
\hline & \multicolumn{4}{|c|}{$\mathrm{IN}(n 30)$} & \multicolumn{4}{|c|}{$\mathrm{RG}(n 32)$} & \multirow[b]{3}{*}{ Between-group change $(P) \S$} \\
\hline & \multicolumn{2}{|c|}{ Baseline $†$} & \multicolumn{2}{|c|}{16 weeks $\ddagger$} & \multicolumn{2}{|c|}{ Baseline† } & \multicolumn{2}{|c|}{16 weeks $\ddagger$} & \\
\hline & Mean & SD & Mean & SD & Mean & SD & Mean & SD & \\
\hline Weight (kg) & 94.4 & $7 \cdot 3$ & $91 \cdot 3^{* \star *}$ & 7.5 & 95.3 & 13.4 & $93.5^{\star *}$ & $14 \cdot 3$ & NS \\
\hline Women & 91.9 & $7 \cdot 1$ & $88 \cdot 7$ & $6 \cdot 6$ & 86.6 & $9 \cdot 0$ & 84.5 & $9 \cdot 1$ & \\
\hline Men & $96 \cdot 8$ & 6.9 & 94.0 & 7.5 & $104 \cdot 0$ & $11 \cdot 2$ & $102 \cdot 6$ & $12 \cdot 7$ & \\
\hline $\mathrm{BMI}\left(\mathrm{kg} / \mathrm{m}^{2}\right)$ & $31 \cdot 2$ & $2 \cdot 7$ & $30 \cdot 1^{\star \star \star}$ & 2.6 & 31.6 & $2 \cdot 7$ & $31 \cdot 0^{* *}$ & $3 \cdot 2$ & NS \\
\hline Women & 32.5 & 2.5 & 31.3 & 1.9 & 31.2 & 2.5 & 30.4 & $2 \cdot 7$ & \\
\hline Men & 29.8 & $2 \cdot 3$ & 29.0 & $2 \cdot 7$ & 32.0 & 2.9 & 31.6 & 3.5 & \\
\hline Waist circumference $(\mathrm{cm})$ & $105 \cdot 2$ & 5.5 & $101 \cdot 1^{\star \star \star}$ & 6.4 & $105 \cdot 8$ & 7.6 & $101 \cdot 9^{\star \star \star}$ & 9.3 & NS \\
\hline Women & 105.6 & 4.9 & 103.0 & 6.4 & $102 \cdot 1$ & 5.9 & 97.3 & 7.4 & \\
\hline Men & $104 \cdot 7$ & $6 \cdot 1$ & $100 \cdot 0$ & $6 \cdot 2$ & 109.5 & $7 \cdot 3$ & $106 \cdot 8$ & 8.7 & \\
\hline Sagittal diameter $(\mathrm{cm})$ & $26 \cdot 7$ & 1.4 & $25 \cdot 3^{\star \star \star}$ & 1.4 & $26 \cdot 7$ & $2 \cdot 4$ & $25 \cdot 7^{\star \star \star}$ & $2 \cdot 8$ & NS \\
\hline Total cholesterol $(\mathrm{mmol} / \mathrm{l})$ & $5 \cdot 27$ & 0.97 & 5.29 & 0.99 & 5.19 & 1.09 & $5 \cdot 18$ & 1.07 & NS \\
\hline LDL-cholesterol (mmol/l) & 3.36 & 0.75 & 3.41 & 0.81 & 3.37 & 0.95 & 3.33 & 0.97 & NS \\
\hline HDL-cholesterol (mmol/li) & 1.18 & 0.25 & 1.23 & 0.29 & 1.22 & 0.33 & 1.25 & 0.30 & NS \\
\hline LDL:HDL ratio & 2.95 & 0.87 & $2 \cdot 88$ & 0.82 & $2 \cdot 88$ & 0.94 & $2 \cdot 78$ & 0.82 & NS \\
\hline Apo-A1 (g/l) & 1.33 & 0.19 & 1.33 & 0.21 & 1.35 & 0.21 & $1 \cdot 34$ & 0.18 & NS \\
\hline Apo-B $(\mathrm{g} / \mathrm{l})$ & $1.05^{\star \star \star}$ & 0.18 & 1.01 & 0.18 & 0.98 & 0.17 & 0.96 & 0.17 & NS \\
\hline Serum TAG $(\mathrm{mmol} / \mathrm{l})$ & 1.57 & 1.01 & 1.39 & 0.59 & 1.37 & 0.51 & 1.31 & 0.63 & NS \\
\hline HDL-TAG (mmol/l) & 0.07 & 0.03 & $0.13^{*}$ & 0.02 & 0.09 & 0.08 & 0.09 & 0.06 & NS \\
\hline $\mathrm{HbA1c}(\%)$ & $4 \cdot 24^{*}$ & 0.31 & $4 \cdot 30^{*}$ & 0.30 & 4.29 & 0.39 & $4 \cdot 37^{\star \star}$ & 0.40 & NS \\
\hline Insulin (mU/l) & 8.31 & $4 \cdot 36$ & $6.89^{*}$ & 3.51 & $14 \cdot 2$ & 23.8 & $10 \cdot 3$ & 8.4 & NS \\
\hline Plasma glucose $(\mathrm{mmol} / \mathrm{l})$ & $5 \cdot 27$ & 0.55 & $5 \cdot 23$ & 0.63 & 5.18 & 0.90 & $5 \cdot 24$ & 0.81 & NS \\
\hline DBP, supine $(\mathrm{mmHg})$ & $80 \cdot 1$ & 8.0 & 79.0 & $7 \cdot 1$ & 79.6 & 6.4 & $79 \cdot 2$ & $6 \cdot 1$ & NS \\
\hline SBP, supine $(\mathrm{mmHg})$ & $130 \cdot 2^{\star \star}$ & $19 \cdot 1$ & $124 \cdot 1^{*}$ & $12 \cdot 5$ & 123.6 & 13.4 & 121.6 & $10 \cdot 9$ & NS \\
\hline 8-iso-PGF $2 a(\mathrm{nmol} / \mathrm{mmol}$ creatine $)$ & 0.29 & 0.08 & 0.31 & 0.07 & 0.32 & 0.14 & 0.30 & 0.13 & $<0.05$ \\
\hline $\mathrm{MDA}(\mu \mathrm{mol} / /)$ & 0.50 & $0 \cdot 10$ & $0.57^{\star \star \star}$ & 0.11 & 0.53 & 0.12 & 0.54 & 0.11 & $<0.05$ \\
\hline PAl-1 (U/ml) & 28.0 & 23.0 & 20.9 & $15 \cdot 7$ & 20.0 & 16.5 & 20.6 & $16 \cdot 3$ & NS \\
\hline$a$-Carotene $(\mathrm{mg} / \mathrm{l})$ & 0.10 & 0.12 & $0.17^{\star \star \star}$ & 0.12 & 0.07 & 0.04 & $0.08^{*}$ & 0.06 & $<0.001$ \\
\hline$\beta$-Carotene $(\mathrm{mg} / \mathrm{l})$ & 0.30 & 0.30 & $0.47^{\star \star \star}$ & 0.34 & 0.24 & 0.14 & 0.26 & 0.17 & $<0.001$ \\
\hline Lutein $(\mathrm{mg} / \mathrm{l})$ & 0.14 & 0.07 & $0 \cdot 16^{* * *}$ & 0.06 & 0.13 & 0.05 & 0.14 & 0.08 & $<0.05$ \\
\hline Lycopene (mg/l) & 0.23 & 0.07 & 0.23 & 0.09 & 0.21 & 0.08 & 0.21 & 0.07 & NS \\
\hline$a$-Tocopherol $(\mathrm{mmol} / \mathrm{l})$ & 1.54 & 0.31 & 1.57 & 0.18 & 1.60 & 0.19 & 1.63 & 0.20 & NS \\
\hline$\gamma$-Tocopherol $(\mathrm{mmol} / \mathrm{l})$ & 0.10 & 0.04 & 0.09 & 0.02 & 0.11 & 0.05 & 0.10 & 0.04 & NS \\
\hline
\end{tabular}

RG, reference; $\mathrm{HbA1c}$, glycated Hb; DBP, diastolic blood pressure; SBP, systolic blood pressure; MDA, plasma malondialdehyde; PAI-1, plasminogen activator inhibitor-1 activity. † Statistically significant differences between IN and RG at baseline: * $P<0.05,{ }^{* \star} P<0.01$

¥ Statistically significant differences between baseline and week 16: ${ }^{\star} P<0.05,{ }^{\star \star} P<0.01,{ }^{\star \star \star} P<0.001$.

$\S$ Between-group change indicates differences between changes from baseline to 16 weeks within the two groups during the intervention.

Supine SBP decreased in the IN group by $6 \mathrm{mmHg}(P<0 \cdot 05)$ and in the RG group by $2 \mathrm{mmHg}$ (NS) at the end of the intervention period without any between-group differences. Supine DBP did not change in either group.

Urinary isoprostane (iso-8-PGF $2 \alpha$ ) levels did not change. MDA levels increased in the IN group $(P<0.05)$ compared with the RG group. PAI-1 levels did not change significantly in either group.

At baseline, $\alpha$ - and $\beta$-carotene levels were higher in the IN group than in the RG group (Table 1). At the end of the intervention, levels had increased in both groups, although the increase was more profound in the IN group $(P<0 \cdot 001)$. Lutein levels were also increased in the IN group $(P<0.05)$ compared with the RG group. No significant changes in $\alpha$ - and $\gamma$-tocopherol levels were seen in either group during the study period.

1-Year follow-up. Among subjects who participated in the follow-up examination 1 year after the end of the intervention period, BW $(P<0.01)$ and BMI $(P<0.01)$ had increased in both groups, although lower compared with baseline, and weight reduction was significantly larger in the IN group than in the RG group $(P<0.05)$ and BMI was lower as well $(P<0.05)$. SAD had decreased further by about $1 \mathrm{~cm}$ in both groups $(P<0 \cdot 001)$, and the change from baseline was larger in the IN group than in the RG group $(P<0 \cdot 05)$. No significant changes in serum lipids were seen but apo-1 levels had increased in both groups $(P<0.05)$. HbA1c levels were significantly higher in both groups $(P<0.001)$, with no differences in plasma glucose levels. Insulin levels had increased in the IN group, but were still lower compared with the RG group. No changes were seen for PAI-1 or SBP in either group, whereas DBP had decreased in the RG group $(P<0.05)$, with no change in the IN group (data not shown).

\section{Food and nutrient intake}

There were no significant differences between the IN and RG groups with respect to the intake of fruits and vegetables at the 
Table 2. Intake of selected foods $(\mathrm{g} / \mathrm{d})$ in the intervention (IN) and the reference (RG) group at baseline and during the intervention period (Mean values and standard deviations)

\begin{tabular}{|c|c|c|c|c|c|c|c|c|}
\hline & \multicolumn{2}{|c|}{ Baseline† } & \multicolumn{2}{|c|}{6 weeks } & \multicolumn{2}{|c|}{12 weeks $\ddagger$} & \multirow[b]{2}{*}{ Mean change } & \multirow[b]{2}{*}{ Between-group change $(P) \S$} \\
\hline & Mean & SD & Mean & SD & Mean & SD & & \\
\hline \multicolumn{9}{|c|}{ Edible fats } \\
\hline IN & 19 & 15 & 23 & 29 & 14 & 15 & -1 & \\
\hline RG & 20 & 17 & 12 & 11 & 15 & 16 & -6 & NS \\
\hline \multicolumn{9}{|c|}{ Cheese } \\
\hline IN & 31 & 22 & 25 & 18 & $22^{*}$ & 17 & -7 & \\
\hline RG & 30 & 22 & 22 & 17 & 27 & 25 & -6 & NS \\
\hline \multicolumn{9}{|l|}{ Milk } \\
\hline IN & 330 & 194 & 238 & 180 & $248^{*}$ & 192 & -83 & \\
\hline$R G$ & 335 & 312 & 291 & 250 & 289 & 228 & -45 & NS \\
\hline \multicolumn{9}{|l|}{ Bread } \\
\hline IN & 104 & 52 & 96 & 58 & 91 & 66 & -10 & \\
\hline$R G$ & 109 & 39 & 115 & 57 & 115 & 54 & 5 & NS \\
\hline \multicolumn{9}{|c|}{ Potatoes } \\
\hline IN & 141 & 76 & 93 & 87 & $89^{\star \star}$ & 67 & -50 & \\
\hline$R G$ & 131 & 95 & 126 & 82 & 115 & 84 & -10 & NS \\
\hline \multicolumn{9}{|c|}{ Root vegetables } \\
\hline IN & 31 & 49 & 66 & 49 & $62^{*}$ & 60 & 33 & \\
\hline$R G$ & 22 & 47 & 31 & 60 & 27 & 45 & 7 & NS \\
\hline \multicolumn{9}{|c|}{ Vegetables and dishes } \\
\hline IN & 207 & 163 & 490 & 198 & $436^{\star \star *}$ & 156 & 256 & \\
\hline$R G$ & 166 & 118 & 185 & 126 & 202 & 137 & 27 & $<0.001$ \\
\hline \multicolumn{9}{|c|}{ Fruits and berries } \\
\hline IN & $202^{\star \star}$ & 149 & 418 & 132 & $394^{\star \star \star}$ & 161 & 204 & \\
\hline$R G$ & 113 & 97 & 221 & 166 & $210^{\star \star \star}$ & 140 & 102 & $<0.05$ \\
\hline \multicolumn{9}{|c|}{ Fruit juice } \\
\hline IN & 78 & 108 & 99 & 133 & 41 & 63 & -8 & \\
\hline$R G$ & 58 & 94 & 51 & 87 & 61 & 101 & -2 & NS \\
\hline \multicolumn{9}{|c|}{ Nuts, seeds } \\
\hline IN & $4 \cdot 1$ & 14.5 & 0.5 & 1.7 & 2.9 & $9 \cdot 3$ & & \\
\hline$R G$ & 0.6 & 3.5 & 1.9 & 9.4 & 1.9 & $5 \cdot 8$ & & NS \\
\hline \multicolumn{9}{|c|}{ Meat including dishes } \\
\hline IN & 120 & 80 & 104 & 71 & 110 & 84 & & \\
\hline$R G$ & 146 & 87 & 123 & 68 & 131 & 97 & & NS \\
\hline \multicolumn{9}{|c|}{ Sausages including dishes } \\
\hline IN & 27 & 28 & 26 & 41 & 26 & 49 & & \\
\hline$R G$ & 36 & 45 & 30 & 44 & 21 & 27 & & NS \\
\hline \multicolumn{9}{|c|}{ Fish including dishes } \\
\hline IN & 61 & 56 & 52 & 45 & 52 & 53 & & \\
\hline$R G$ & 31 & 39 & 48 & 50 & 46 & 62 & & NS \\
\hline \multicolumn{9}{|c|}{ Sweet bakery products } \\
\hline IN & 56 & 46 & 27 & 28 & $35^{\star}$ & 39 & -25 & \\
\hline$R G$ & 48 & 66 & 19 & 25 & $25^{\star}$ & 26 & -26 & NS \\
\hline \multicolumn{9}{|c|}{ Ice-cream } \\
\hline IN & 23 & 32 & 2 & 7 & 8 & 14 & $-18^{\star}$ & \\
\hline$R G$ & 20 & 44 & 8 & 18 & 8 & 18 & -12 & NS \\
\hline Soft dri & & & & & & & & \\
\hline IN & $112^{*}$ & 226 & 61 & 137 & 57 & 83 & -53 & \\
\hline$R G$ & 63 & 121 & 63 & 131 & 38 & 101 & -13 & NS \\
\hline
\end{tabular}

† Statistically significant differences between IN and RG at baseline: * $P<0.05,{ }^{* *} P<0.01$.

‡ Statistically significant differences between baseline and week 12: ${ }^{*} P<0.05,{ }^{* \star} P<0.01,{ }^{* \star *} P<0.001$.

$\S$ Between-group change indicates differences between changes from baseline to 12 weeks within the two groups during the intervention.

study start (Table 2). After 6 weeks, the intake of both fruits and vegetables had increased about 2 -fold in the IN group (Fig. 2), which was largely maintained at week $12(P<0.001)$. The intake of fruits also increased in the RG group $(P<0 \cdot 01)$, but was less than that in the IN group. The intake of fruit juices was lower $(P<0.05)$ at week 12 in the IN group, with no changes in the RG group. Changes in the intakes of other food groups during the study period were relatively limited (Table 2).

Reported energy intake decreased significantly during the study period in both groups, with no between-group differences.
The percentage of energy (E\%) from total fat, SFA and MUFA decreased at week 12, with no between-group differences (Table 3). E\% from carbohydrates and monosaccharides increased significantly in both groups, whereas E\% from sucrose tended to decrease significantly only in the RG group. No significant changes were seen for the proportion of major fatty acids in the diet (data not shown).

During the study period, the intake of $\beta$-carotene, folate, vitamin $\mathrm{C}$ and dietary fibre increased significantly in the IN compared with the RG group (Table 3). Changes for other micronutrients were limited. 


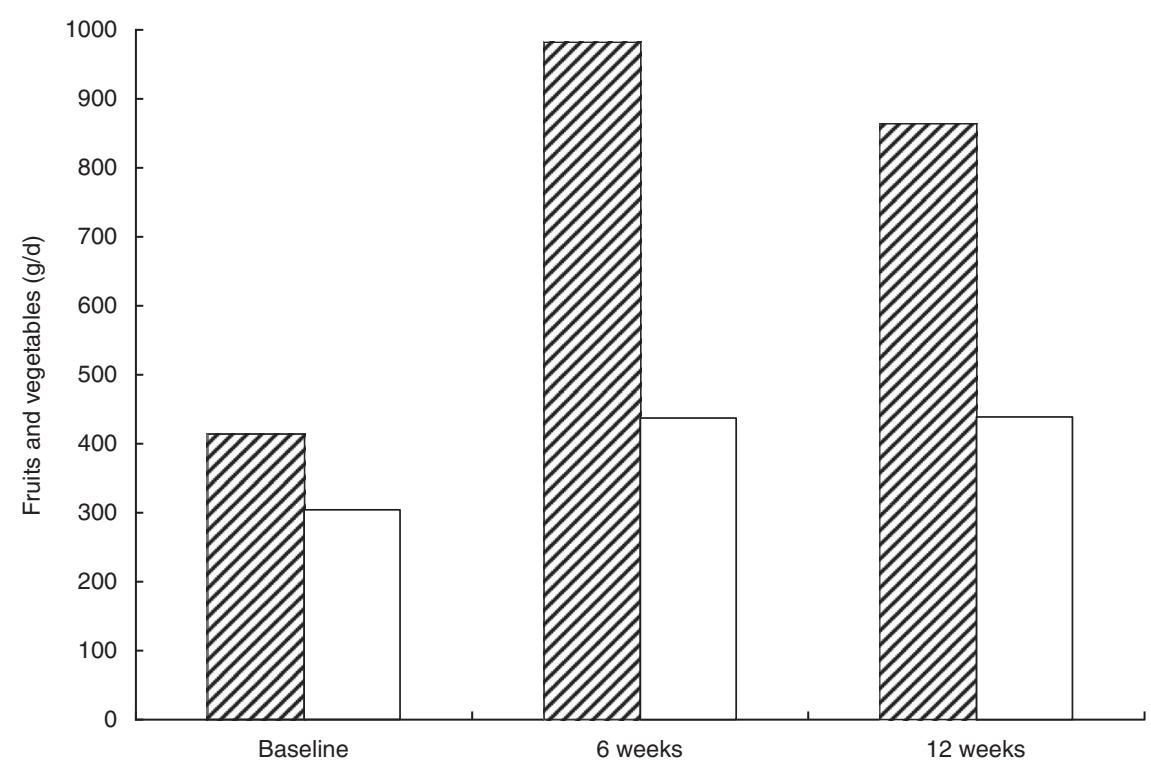

Fig. 2. Mean total intake of fruits and vegetables (excluding fruit juice) at baseline and during the study period. $\square$, Intervention; $\square$, usual care.

1-Year follow-up. At follow-up, intake of fruits was significantly higher in the IN $(P<0.05)$ and in the RG group $(P<0 \cdot 01)$ compared with baseline. Reported energy intakes were significantly lower compared with baseline in both groups $(P<0.05)$, whereas $\mathrm{E} \%$ for macronutrients and intakes of most micronutrients were not significantly different from baseline in either group (data not shown).

\section{Discussion}

The main aim of the present study was to investigate the effects of an increased intake of fruits and vegetables on several anthropometric and metabolic markers associated with risk of CVD and type 2 diabetes, but also to study effects on other dietary changes. An intake of at least $500 \mathrm{~g} / \mathrm{d}$ was the target, and an ample amount of fruits and vegetables was provided to the subjects in the IN group together with general dietary advice and recipes.

\section{Dietary changes}

In the IN group, the total intake of fruits and vegetables (excluding fruit juice) increased about 2-fold during the intervention (Fig. 2). This shows that the intervention was successful and that most subjects ate the provided amounts of fruits and vegetables $(\geq 500 \mathrm{~g} / \mathrm{d})$. The fact that the RG group increased the intake of fruits, but not vegetables, during the study period could be interpreted as changes in the intake of fruits are easier to achieve than changes in the intake of vegetables. There was also a trend for decreased intake of sugar-containing foods, indicating an influence of the dietary advice.

Reported energy intake decreased in both groups during the study period and the dietary composition changed (Table 3). Some under-reporting was evident, but changes in reported energy intakes were similar in both groups. $\mathrm{E} \%$ from fat decreased, whereas the intake of monosaccharides (both in grams and as $\mathrm{E} \%$ ) increased significantly in the IN group, which can be attributed to the increased intake of fruits and vegetables. Intake of sucrose (as $\mathrm{E} \%$ ) decreased in the RG group, with no significant changes in the IN group - the latter reflecting the increased intake of fruits. Pronounced increases in the intakes of $\beta$-carotene, folate, vitamin $\mathrm{C}$ and dietary fibre were seen in the IN group during the study, and plasma concentrations of $\alpha$-and $\beta$-carotene also increased, thereby confirming the dietary data.

At the follow-up, 1 year after the completion of the intervention period, the total intake of fruits and vegetables was still higher compared with baseline, especially in the IN group. This indicates that the increased availability in the IN group during the study period had a longer-lasting influence on behaviour than general dietary advice.

\section{Effects on anthropometry and clinical markers}

At the end of the 16-week intervention period, favourable changes in certain anthropometric measures and markers of glucose metabolism were seen, and changes tended to be more pronounced in the IN group. Insulin levels decreased in both groups, significant for the IN group only $(P<0.05)$. No significant between-group changes were seen for BP, major serum lipids and apo, or plasma glucose and HbA1c levels. Power calculations were carried out for differences in BMI. The relatively wide variation in initial $\mathrm{BP}$ reduced the power to detect significant differences in BP between groups during the intervention.

The results of the present study are in line with other interventional studies, which indicate favourable effects of increased intakes of fruits and vegetables on $\mathrm{BW}^{(11,13)}$ and on some markers of the metabolic syndrome ${ }^{(10-12)}$. Other studies have, similar to our study, shown minor or no clear effects on serum lipids ${ }^{(11,17,38-40)}$. We found limited effects on BP, similar to two 
Table 3. Average daily intake of energy, proximates, dietary fibre and some micronutrients in the intervention (IN) and reference (RG) groups (Mean values and standard deviations)

\begin{tabular}{|c|c|c|c|c|c|c|c|c|c|}
\hline \multirow[b]{2}{*}{ Nutrients } & \multirow[b]{2}{*}{ Group } & \multicolumn{2}{|c|}{ Baseline† } & \multicolumn{2}{|c|}{6 weeks } & \multicolumn{2}{|c|}{12 weeks $\ddagger$} & \multirow[b]{2}{*}{ Mean change } & \multirow[b]{2}{*}{ Between-group change $(P) \S$} \\
\hline & & Mean & SD & Mean & SD & Mean & SD & & \\
\hline \multirow[t]{2}{*}{ Energy (kJ) } & IN & 9860 & 2150 & 8590 & 1860 & $8320^{\star \star}$ & 2770 & -1400 & \\
\hline & $R G$ & 9180 & 2870 & 7830 & 2420 & $7300^{\star \star *}$ & 1780 & -1620 & NS \\
\hline \multirow[t]{2}{*}{ Protein (E\%) } & IN & $16 \cdot 3$ & 2.3 & $16 \cdot 9$ & 2.7 & $17 \cdot 4^{\star}$ & 2.9 & 0.8 & \\
\hline & $R G$ & $16 \cdot 6$ & $3 \cdot 3$ & $18 \cdot 2$ & $3 \cdot 2$ & $18 \cdot 2^{*}$ & $2 \cdot 7$ & 1.6 & NS \\
\hline \multirow[t]{2}{*}{ Fat $(E \%)$} & IN & $30 \cdot 8$ & 5.9 & $27 \cdot 7$ & $7 \cdot 2$ & $25 \cdot 6^{* * *}$ & 4.9 & $-4 \cdot 2$ & \\
\hline & $R G$ & 31.4 & $6 \cdot 1$ & 28.4 & $6 \cdot 3$ & $27 \cdot 5^{\star}$ & $5 \cdot 6$ & $-3 \cdot 4$ & NS \\
\hline \multirow[t]{2}{*}{ SFA (E\%) } & IN & $12 \cdot 7$ & $3 \cdot 0$ & $10 \cdot 4$ & $3 \cdot 1$ & $10 \cdot 2^{\star \star \star}$ & $2 \cdot 4$ & $-2 \cdot 4$ & \\
\hline & $R G$ & $12 \cdot 8$ & $2 \cdot 7$ & 11.4 & $2 \cdot 6$ & $10 \cdot 9^{* *}$ & $2 \cdot 7$ & $-1 \cdot 7$ & NS \\
\hline \multirow[t]{2}{*}{ MUFA (E\%) } & IN & 11.4 & 2.5 & $10 \cdot 1$ & $3 \cdot 1$ & $9 \cdot 4^{\star \star}$ & $2 \cdot 3$ & $-1 \cdot 6$ & \\
\hline & $R G$ & $12 \cdot 0$ & $2 \cdot 7$ & 10.4 & 2.5 & $10 \cdot 4^{\star}$ & $2 \cdot 3$ & $-1 \cdot 6$ & NS \\
\hline \multirow[t]{2}{*}{ PUFA (E\%) } & IN & 4.5 & 1.2 & $5 \cdot 0$ & $2 \cdot 2$ & 3.9 & 1.0 & 0.0 & \\
\hline & $R G$ & 4.7 & 1.7 & 4.5 & $2 \cdot 0$ & 4.7 & $2 \cdot 6$ & 0.1 & NS \\
\hline \multirow[t]{2}{*}{ Carbohydrate (E\%) } & IN & $50 \cdot 1$ & $7 \cdot 3$ & 53.5 & $7 \cdot 3$ & $54 \cdot 2^{*}$ & $6 \cdot 7$ & 3.8 & \\
\hline & $R G$ & 48.9 & 7.4 & 51.9 & 7.5 & $52 \cdot 6^{*}$ & $6 \cdot 3$ & $3 \cdot 3$ & NS \\
\hline \multirow[t]{2}{*}{ Sucrose (E\%) } & IN & 8.6 & 3.6 & 8.4 & $3 \cdot 1$ & 8.7 & $2 \cdot 7$ & -0.0 & \\
\hline & $R G$ & $9 \cdot 0$ & 4.3 & $7 \cdot 2$ & 3.6 & $7 \cdot 2^{\star}$ & $3 \cdot 3$ & -1.9 & NS \\
\hline \multirow[t]{2}{*}{ Monosaccharides ( $\mathrm{E} \%$ ) } & IN & 8.0 & $3 \cdot 8$ & $12 \cdot 3$ & 3.8 & $12 \cdot 0$ & 3.4 & $4 \cdot 2$ & \\
\hline & $R G$ & $6 \cdot 3^{\star \star}$ & $2 \cdot 6$ & 8.3 & 4.2 & $8 \cdot 1^{\star \star}$ & 3.4 & 1.9 & $<0.01$ \\
\hline \multirow[t]{2}{*}{ Alcohol (E\%) } & IN & $2 \cdot 9$ & 4.3 & $2 \cdot 0$ & $2 \cdot 8$ & 2.9 & $6 \cdot .5$ & -0.4 & \\
\hline & $R G$ & 3.2 & $5 \cdot 1$ & 1.7 & $2 \cdot 1$ & 1.8 & 2.6 & -1.5 & NS \\
\hline \multirow[t]{2}{*}{ Retinol $(\mu \mathrm{g})$} & IN & 783 & 453 & 764 & 1042 & $533^{\star \star}$ & 394 & -178 & \\
\hline & $R G$ & 930 & 1350 & 715 & 842 & 751 & 1020 & -197 & NS \\
\hline \multirow[t]{2}{*}{$\beta$-Carotene (mg) } & IN & 2.90 & $3 \cdot 21$ & 9.12 & $5 \cdot 34$ & $7 \cdot 88^{\star \star \star}$ & 4.63 & $5 \cdot 70$ & \\
\hline & $\mathrm{RG}$ & $2 \cdot 32$ & $2 \cdot 71$ & 3.74 & 4.26 & 3.37 & 3.18 & 1.23 & $<0.001$ \\
\hline \multirow[t]{2}{*}{$a$-Tocopherol, mg } & IN & $9 \cdot 6$ & $2 \cdot 1$ & $11 \cdot 2$ & $4 \cdot 0$ & 9.5 & 3.1 & 0.7 & \\
\hline & $R G$ & 8.7 & 3.5 & 8.0 & 3.4 & 7.5 & 2.5 & -0.9 & $<0.05$ \\
\hline \multirow[t]{2}{*}{ Folate $(\mu \mathrm{g})$} & IN & 312 & 92 & 516 & 230 & $438^{\star \star \star}$ & 127 & 162 & \\
\hline & $R G$ & 284 & 80 & 306 & 102 & 295 & 92 & 16 & $<0.001$ \\
\hline \multirow[t]{2}{*}{ Vitamin C (mg) } & IN & 123 & 85 & 298 & 157 & $221^{\star \star \star}$ & 72 & 134 & \\
\hline & $R G$ & 92 & 61 & 112 & 62 & 118 & 67 & 24 & $<0.001$ \\
\hline \multirow[t]{2}{*}{ K (g) } & IN & 4.00 & 0.96 & 4.54 & 1.31 & $4 \cdot 38$ & $1 \cdot 11$ & 0.44 & \\
\hline & $R G$ & 3.66 & 1.35 & 3.56 & 0.94 & 3.50 & 0.87 & -0.13 & NS \\
\hline $\mathrm{Na}(\mathrm{g})$ & IN & 3.48 & 0.74 & $3 \cdot 25$ & 1.25 & $3.05^{\star}$ & $1 \cdot 15$ & -0.35 & \\
\hline & $R G$ & 3.43 & $1 \cdot 12$ & 3.22 & 0.80 & $3.03^{*}$ & 0.81 & -0.31 & NS \\
\hline $\mathrm{Mg}(\mathrm{mg})$ & IN & 403 & 95 & 436 & 114 & 435 & 121 & 29 & \\
\hline & $R G$ & $354^{\star \star}$ & 101 & 361 & 101 & 351 & 85 & 2 & NS \\
\hline Cholesterol (mg) & IN & 372 & 97 & 276 & 144 & 263 & 136 & -105 & \\
\hline & $R G$ & 373 & 186 & 297 & 131 & 316 & 157 & -67 & NS \\
\hline Dietary fibre (g) & IN & $23 \cdot 7^{\star}$ & 8.5 & 38.3 & $10 \cdot 7$ & $37 \cdot 0^{\star \star \star \star}$ & $12 \cdot 8$ & 13.6 & \\
\hline & RG & $19 \cdot 2$ & 5.9 & 24.7 & 8.7 & $24 \cdot 2^{\star \star \star}$ & 7.8 & $5 \cdot 2$ & $<0.001$ \\
\hline
\end{tabular}

$E \%$, percentage of energy.

† Statistically significant differences between IN and RG at baseline: * $P<0.05,{ }^{* *} P<0.01$.

¥ Statistically significant differences between baseline and week 12: ${ }^{\star} P<0.05,{ }^{\star \star} P<0.01,{ }^{\star \star \star} P<0.001$.

$\S$ Between-group change indicates differences between changes from baseline to 12 weeks within the two groups during the IN.

other studies ${ }^{(17,40)}$. In other studies, increased intake of fruits and vegetables resulted in lower BP compared with the control $^{(9,11,41)}$. The somewhat diverging results in different studies may partly be due to differences in design, study populations, baseline diets, amounts and types of fruits and vegetables consumed during intervention and duration (see online Supplementary Table S1).

A few intervention studies have investigated the effects of increased intake of fruits and vegetables on glucose and insulin response and markers of inflammation. Flood et al. ${ }^{(12)}$ randomised subjects with previous colorectal adenoma to advice on a low-fat, high-fibre and high fruit and vegetable diet or general dietary guidance. After 4 years, no differences were seen for serum concentrations of insulin, glucose, IGF-I (insulin-like growth factor-1) and IGFBP-3 (insulin-like growth factor-binding protein). In our study, insulin concentrations decreased in the IN group, whereas no consistent pattern was seen for glucose concentrations or markers of inflammation. No effects on insulin resistance were seen in one study after increased intakes from about $160 \mathrm{~g} / \mathrm{d}$ up to $<500 \mathrm{~g} / \mathrm{d}$ during 16 weeks $^{(16)}$. In a systematic review, including six prospective cohort studies, no consistent association with diabetes risk was found for fruit and vegetable intake ${ }^{(15,42)}$. However, an inverse association was found for intake of green leafy vegetables. In addition, biomarkers of fruit and vegetable intake were found to be inversely related to type 2 diabetes in a nested case-control study within the European Prospective Investigation into Cancer and Nutrition (EPIC) cohort $2015^{(43)}$. Dietary intake of carotenoids was also inversely related to type 2 diabetes in the Dutch cohort of the EPIC study ${ }^{(44)}$.

A diet rich in fruits and vegetables has in cohort studies been associated with lower $\mathrm{BP}^{(45)}$, and in other studies with longterm health benefits, for example, lower risk of some cancers 
or colorectal adenomas ${ }^{(2,22,24,46,47)}$ CVD $^{(18,19)}$ and total mortality ${ }^{(19,20)}$. Results from mainly epidemiological studies have shown some evidence for a relationship between fruit and vegetable intakes and $\mathrm{BW}^{(13,14,25)}$

The strengths of this study include controlled intervention with ample supply of fruits and vegetables in the IN group, resulting in high adherence. The dietary quality of the study groups was better compared with the general adult population already at the beginning of the study, including a higher intake of fruits and vegetables, which may have resulted in less pronounced differences in the study outcomes between the IN and RG group, especially as improvements in the diet was seen in the RG group as well.

\section{Conclusions}

Compared with subjects who received general dietary advice, provision of ample amounts of fruits and vegetables led to substantial increases in fruit and vegetable intake among overweight subjects. The increased intake was accompanied by favourable changes in BW and other anthropometric measures and insulin levels, and these changes tended to be more pronounced than in subjects given dietary advice only. These changes may, in combination with increased serum concentrations of carotenoids, and vitamin $\mathrm{C}$ and folate intakes, have health benefits in the long term with respect to, for example, risk of CVD, certain cancers and type 2 diabetes.

\section{Acknowledgements}

The authors thank Siv Tengblad for eminent analytical support and Professor Samar Basu for management of the isoprostane analysis.

The study was supported by a grant from the Swedish Council for Forestry and Agricultural Research. Additional funding was obtained from Uppsala county council; ICA Handlarna AB supported the study with all the fresh vegetables, roots, fruits and berries for the whole study period. Nestlé Sverige AB supported the study by providing all deep-frozen vegetables and vegetable mixes throughout the whole study period (Findus products).

The authors' contributions are as follows: A. J. had main responsibility for the study design and for conducting the study.

B. K. and B. V. assisted in design and evaluation. W. B. had main responsibility for compilation and statistical analysis. All authors contributed to the writing of the manuscript.

The authors declare that there are no conflicts of interest.

\section{Supplementary material}

For supplementary material/s referred to in this article, please visit http://dx.doi.org/10.1017/S0007114516000970

\section{References}

1. Danaei G, Finucane M, Lu Y, et al. (2011) National, regional, and global trends in fasting plasma glucose and diabetes prevalence since 1980: systematic analysis of health examination surveys and epidemiological studies with 370 countryyears and 2.7 million participants. Lancet 378, 31-40.

2. World Cancer Research Fund \& American Institute for Cancer Research (2007) Food, Nutrition, and Physical Activity, and the Prevention of Cancer: A Global Perspective. Washington, DC: AICR.

3. Wang YC, McPherson K, Marsh T, et al. (2011) Health and economic burden of the projected obesity trends in the USA and the UK. Lancet 378, 815-825.

4. Nordic Council of Ministers (2014) Nordic Nutrition Recommendations 2012. Integrating Nutrition and Physical Activity. Copenhagen: NCM.

5. Nordic Council of Ministers (2004) Nordic Nutrition Recommendations 2004. Integrating Nutrition and Physical Activity, 4th ed. Copenhagen: Nordic Council of Ministers.

6. Nishida C \& Martinez Nocito F (2007) FAO/WHO scientific update on carbohydrates in human nutrition: introduction. Eur J Clin Nutr 61, S1-S2.

7. Food and Agriculture Organization (2010) Fats and Fatty Acids in Human Nutrition. Report of an Expert Consultation. 10-14 November 2008, Geneva. FAO Food and Nutrition Paper, no. 91]. Rome: Food and Agricultural Organisation of the United Nations.

8. Appel L, Moore T, Obarzanek E, et al. (1997) The effect of dietary patterna on blood pressure: results from the Dietary Approaches top Stop Hypertension (DASH) trial. N Engl J Med 336, 1117-1124.

9. John J, Ziebland S, Yudkin P, et al. (2002) Oxford Fruit and Vegetable Study Group. Effects of fruit and vegetable consumption on plasma antioxidant concentrations and blood pressure: a randomised controlled trial. Lancet 359, 1969-1974.

10. Watzl B, Kulling S, Möseneder J, et al. (2005) A 4-wk intervention with high intake of carotenoid-rich vegetables and fruit reduces plasma C-reactive protein in healthy, nonsmoking men. Am J Clin Nutr 82, 1052-1058.

11. Svendsen M, Blomhoff R, Holme I, et al. (2007) The effect of an increased intake of vegetables and fruit on weight loss, blood pressure and antioxidant defense in subjects with sleep related breathing disorders. Eur J Clin Nutr 61, 1301-1311.

12. Flood A, Mai V, Pfeiffer R, et al. (2008) The effects of a highfruit and -vegetable, high-fiber, low-fat dietary intervention on serum concentrations of insulin, glucose, IGF-I and IGFBP-3. Eur J Clin Nutr 62, 186-196.

13. Rolls B, Ello-Martin J \& Tohill B (2004) What can intervention studies tell us about the relationship between fruit and vegetable consumption and weight management? Nutr Rev 62, 1-17.

14. Alinia S, Hels O \& Tetens I (2009) The potential association between fruit intake and body weight - a review. Obes Rev 10, 639-647.

15. Boeing H, Bechthold A, Bub A, et al. (2012) Critical review: vegetables and fruit in the prevention of chronic diseases. Eur J Nutr 51, 637-663.

16. Wallace IR, McEvoy CT, Hunter SJ, et al. (2013) Doseresponse effect of fruit and vegetables on insulin resistance in people at high risk of cardiovascular disease: a randomized controlled trial. Diabetes Care 36, 3888-3896.

17. McEvoy CT, Wallace IR, Hamill LL, et al. (2015) Increasing fruit and vegetable intake has no dose-response effect on conventional cardiovascular risk factors in overweight adults at high risk of developing cardiovascular disease. J Nutr $\mathbf{1 4 5}$, $1464-1471$.

18. Hu D, Huang J, Wang Y, et al. (2014) Fruits and vegetables consumption and risk of stroke: a meta-analysis of prospective cohort studies. Stroke 45, 1613-1619. 
19. Wang X, Ouyang Y, Liu J, et al. (2014) Fruit and vegetable consumption and mortality from all causes, cardiovascular disease, and cancer: systematic review and dose-response meta-analysis of prospective cohort studies. BMJ 349, g4490.

20. Hjartåker A, Knudsen M, Tretli S, et al. (2015) Consumption of berries, fruits and vegetables and mortality among 10,000 Norwegian men followed for four decades. Eur J Nutr 54, 599-608.

21. Nomura A, Wilkens L, Murphy S, et al. (2008) Association of vegetable, fruit, and grain intakes with colorectal cancer: the Multiethnic Cohort Study. Am J Clin Nutr 88, $730-737$.

22. George S, Park Y, Leitzmann M, et al. (2009) Fruit and vegetable intake and risk of cancer: a prospective cohort study. Am J Clin Nutr 89, 347-353.

23. van Duijnhoven $\mathrm{F}$, Bueno-De-Mesquita $\mathrm{H}$, Ferrari $\mathrm{P}$, et al. (2009) Fruit, vegetables, and colorectal cancer risk: the European Prospective Investigation into Cancer and Nutrition. Am J Clin Nutr 89, 1441-1452.

24. Yeh M, Moysich K, Jayaprakash V, et al. (2009) Higher intakes of vegetables and vegetable-related nutrients are associated with lower endometrial cancer risks. J Nutr 139, 317-322.

25. Fogelholm M, Anderssen S, Gunnarsdottir I, et al. (2012) Dietary macronutrients and food consumption as determinants of long-term weight change in adult populations: a systematic literature review. Food Nutr Res 56, 1-45.

26. Becker W \& Hagman U (1999) More fruit and vegetables is beneficial for health (in Swedish). Vår Föda 51, 24-28.

27. Becker W \& Pearson M (2002) Dietary Habits and Nutrient Intake in Sweden 1997-98. Uppsala: National Food Agency; (in Swedish with English summary).

28. Amcoff E, Edberg A, Enghardt Barbieri H, et al. (2012) Riksmaten - Adults 2010-11. Uppsala: National Food Agency; (in Swedish).

29. National Food Agency (2009) The keyhole symbol, [NF Agency, editor]. Uppsala.

30. National Food Agency (2008) The plate model. http://www. livsmedelsverket.se/matvanor-halsa-miljo/kostrad-och-matvanor/ tallriksmodellen/?_t_id=1B2M2Y8AsgTpgAmY7PhCfg\%3d\%3d\& t_q=tallriksmodellen\&_t_tags=language $\% 3$ asv $\% 2 \mathrm{csiteid} \% 3 \mathrm{a} 67 \mathrm{f} 9 \mathrm{C}$ 486-281d-4765-ba72-ba3914739e3b\&_t_ip=10.177.14.177.14.234 \&_t_hit.id=Livs_Common_Model_PageTypes_ArticlePage/_3156 ac1a-58df-4059-af73-38e0e3d7c72a_sv\&_t_hit.pos=1 (accessed March 2016).

31. Krotokiewski M, Björntorp P, Sjöström L, et al. (1983) Impact of obesity on metabolism in men and women. Importance of regional adipose tissue distribution. J Clin Invest 72, 1150-1162.

32. Seigler L \& Wu W (1981) Separation of serum high-density lipoprotein for cholesterol determination: ultracentrifugation vs precipitation with sodium phosphotungstate and magnesium chloride. Clin Chem 27, 838-841.
33. Ohrvall M, Tengblad S \& Vessby B (1993) Lower tocopherol serum levels in subjects with abdominal adiposity. I Intern Med 234, 53-60.

34. Thurnham D, Davies J, Crump B, et al. (1986) The use of different lipids to express serum tocopherol: lipid ratios for the measurement of vitamin E status. Clin Biochem 23, 514-520.

35. Rytter E, Vessby B, Asgård R, et al. (2010) Supplementation with a combination of antioxidants does not affect glycaemic control, oxidative stress or inflammation in type 2 diabetes subjects. Free Radic Res 44, 1445-1453.

36. Ohrvall M, Tengblad S, Ekstrand B, et al. (1994) Malondialdehyde concentration in plasma is inversely correlated to the proportion of linoleic acid in serum lipoprotein lipids. Atherosclerosis 108, 103-110.

37. Basu S (1998) Radioimmunoassay of 8-iso-prostaglandin F2alpha: an index for oxidative injury via free radical catalysed lipid peroxidation. Prostaglandins Leukot Essent Fatty Acids 58, 319-325.

38. Zino S, Skeaff M, Williams S, et al. (1997) Randomised controlled trial of effect of fruit and vegetable consumption on plasma concentrations of lipids and antioxidants. BMJ 314, 1787-1791.

39. Smith-Warner S, Elmer P, Tharp T, et al. (2000) Increasing vegetable and fruit intake: randomized intervention and monitoring in an at-risk population. Cancer Epidemiol Biomarkers Prev 9, 307-317.

40. Broekmans W, Klopping-Ketelaars W, Kluft C, et al. (2001) Fruit and vegetables and cardiovascular risk profile: a diet controlled intervention study. Eur J Clin Nutr 55, 636-642.

41. Adebawo O, Salau B, Ezima E, et al. (2006) Fruits and vegetables moderate lipid cardiovascular risk factor in hypertensive patients. Lipids Health Dis 5, 14.

42. Carter P, Gray L \& Troughton J (2010) Fruit and vegetable intake and incidence of type 2 diabetes mellitus: systematic review and meta-analysis. BMJ 341, c4229.

43. Cooper AJ, Sharp SJ, Luben RN, et al. (2015) The association between a biomarker score for fruit and vegetable intake and incident type 2 diabetes: the EPIC-Norfolk study. Eur J Clin Nutr 69, 449-454.

44. Sluijs I, Cadier E, Beulens JW, et al. (2015) Dietary intake of carotenoids and risk of type 2 diabetes. Nutr Metab Cardiovasc Dis 25, 376-381.

45. Dauchet L, Kesse-Guyot E, Czernichow S, et al. (2007) Dietary patterns and blood pressure change over 5-y follow-up in the SU.VI.MAX cohort. Am J Clin Nutr 85, 1650-1656.

46. Wu H, Dai Q, Shrubsole M, et al. (2009) Fruit and vegetable intakes are associated with lower risk of colorectal adenomas. J Nutr 139, 340-344.

47. Boffetta P, Couto E, Wichmann J, et al. (2010) Fruit and vegetable intake and overall cancer risk in the European Prospective Investigation into Cancer and Nutrition (EPIC). I Natl Cancer Inst 102, 529-537. 